\title{
HEART CHANGES IN ALKALOSIS
}

\author{
BY \\ J. STEWART LAWRENCE AND E. N. ALLOTT
}

Received March 11, 1943

\begin{abstract}
Electrocardiographic findings in alkalosis were first noted in 1922 by Carter and Andrus, who observed that the Q-T interval was prolonged by more than 30 per cent in three of their cases; this was associated with a lowering of the blood calcium. Barker, Arbor, Shrader, and Ronzoni (1939) produced artificial alkalosis by voluntary overventilation or by ingestion of sodium bicarbonate, the Q-T interval being slightly increased by the latter procedure. In a hysterical patient with hyperventilation a similar effect was produced, but this did not exceed normal limits; a reduction of the $\mathrm{T}$ wave was also observed.

An opportunity occurred recently of studying the cardiac function in alkalosis.
\end{abstract}

\section{CASE REPORT}

A woman of 47 was admitted to St. Nicholas Hospital on December 4, 1941. She stated that she had been well till three years previously when she began to suffer from occasional vomiting after meals and during the night. Abdominal pain was troublesome at times and was relieved by vomiting or alkalis. Since then she had never been free from the trouble for more than a day at a time. For the few weeks before admission the severity of the attacks increased and she took MacLean's powder frequently. On the day before admission she suddenly felt as though about to die and her hands and arms went into spasms and felt numb and tingling. This soon passed off, but returned the following morning. On admission, both arms were found to be in tonic spasm with elbows and wrists flexed, fingers and thumb in the position of main d'accoucheur. The abdomen was held tense. Blood taken at this time had a bicarbonate content of 150 vol., a blood urea of $132 \mathrm{mg}$., and a serum calcium of $10.2 \mathrm{mg}$., each per 100 c.c. Next day she became confused, disorientated in time, suspicious, and apprehensive. At this time she was having repeated cramps in her limbs and her tongue was dry and thickly coated. After administration of 5 c.c. of 5 per cent calcium chloride intravenously, she improved considerably.

On the third day in hospital she was again restless and confused, and kept trying to get out of bed with the intention of going home. Every piece of paper she could lay hands on (including her case notes) she would fold up and put in her bag. During the course of the morning she vomited three pints of greenish fluid. On examination she was found to be very emaciated, but had a good colour. The Chvostek sign was negative, Trouseau faintly positive. The blood pressure was $100 / 60$. The heart was regular at a rate of 75; the two sounds were unusually close together but the apex beat was not displaced. The abdomen showed marked peristalsis, apparently gastric in origin, over almost its entire extent, and splashing could be elicited over a wide area. The temperature was $98.8^{\circ}$, respirations 22 . The urine was neutral and contained much albumin. A cardiogram showed low voltage complexes in lead I and a greatly prolonged Q-T interval $(0.56 \mathrm{sec}$.).

The serum bicarbonate at this time was 150 vol., chloride $166 \mathrm{mg}$., sodium $320 \mathrm{mg}$., and blood urea $310 \mathrm{mg}$., each per 100 c.c.; the B.S.R. was $52 \mathrm{~mm}$. in the first hour and the circulation time (arm to tongue) 30 seconds.

An intravenous drip of 2 per cent saline at 120 drops a minute and stomach wash outs with saline were started. Improvement was rapid and by the fifth day the patient was normal mentally and less dehydrated in appearance. The serum bicarbonate had now fallen to $135 \mathrm{vol}$. and the chloride risen to $282 \mathrm{mg}$. and the blood urea was $210 \mathrm{mg}$., each per 100 c.c. A barium meal showed a large stomach with increased peristalsis, with obstruction at the pylorus, and a small prepyloric ulcer. By the seventh day the serum bicarbonate was 125 vol., chloride $319 \mathrm{mg}$., sodium $305 \mathrm{mg}$., and urea $42 \mathrm{mg}$., each per 100 c.c. On the eighth day, laparotomy was performed by Mr. Martin under local anæsthesia and pentothal. There was much prepyloric scarring with no ascertainable patency from 


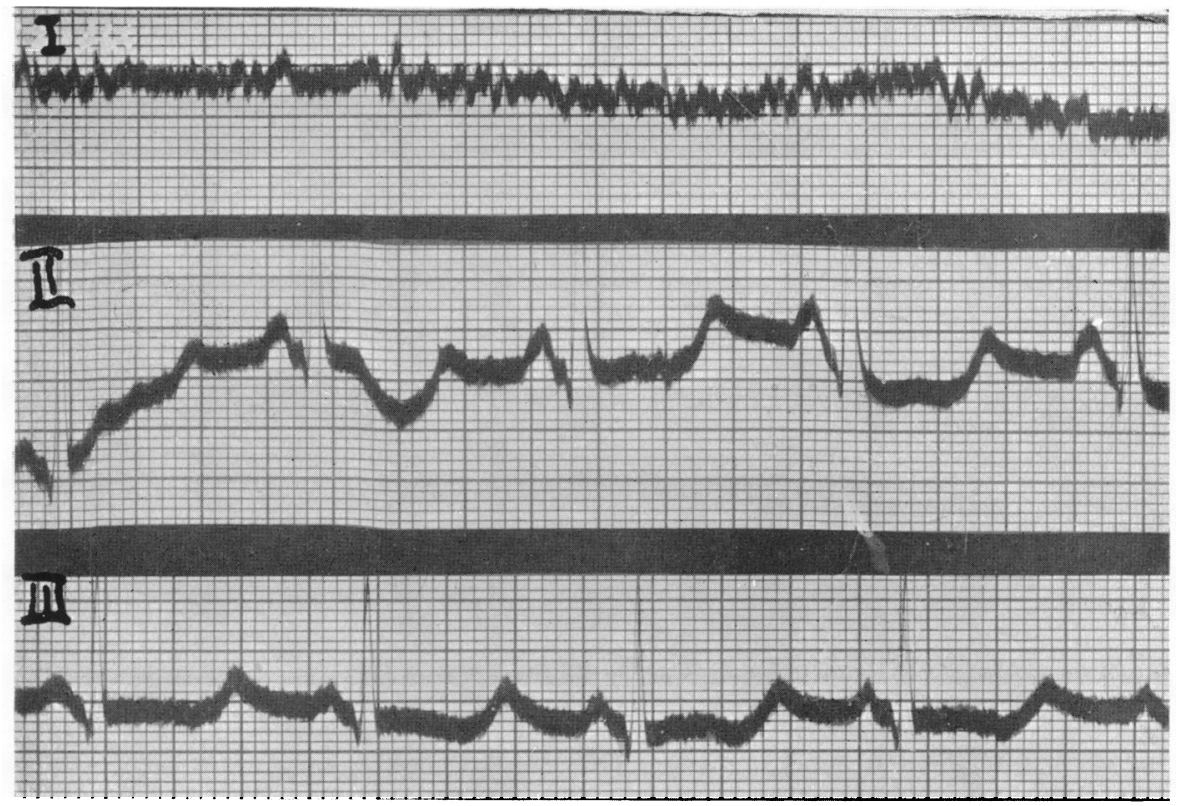

FIG. 1.-Electrocardiogram showing prolongation of the Q-T interval $(0.56 \mathrm{sec}$.). There are some extrinsic excursions, especially in lead II.

external tests. The stomach was enormously dilated. A gastro-enterostomy was performed. During the operation the pulse became very feeble, the veins in the neck engorged, and the breathing shallow and infrequent; cyanosis was present despite a very light stage of anæsthesia, but oxygen resulted in a rapid improvement which was maintained for the remainder of the operation. Despite continued administration of saline intravenously the patient died two days later. A post-mortem examination was refused.

\section{Discussion}

Bazett (1920) was the first to use the electrocardiograph to study the duration of systole in relation to the heart rate. He measured the Q-T interval (from beginning of $Q$ to end of $\mathrm{T}$ ) in lead II in a number of normal men and women, expressing the result by the formula: duration of systole $=K \sqrt{\text { duration }}$ of cardiac cycle. $K$ was found to average 0.37 in men and 0.40 in women, the limits being 0.36 to 0.48 . An increase of the relative length of systole has been found in conditions associated with hypocalcæmia, notably hypoparathyroidism, and to a less extent in diabetic coma, rheumatic carditis, cardiac enlargement, heart block, and chronic nephritis, according to Graybiel and White (1941). Hypocalcæmia would also explain the changes noted in their cases of alkalosis by Carter and Andrus. In the present case the $\mathrm{Q}-\mathrm{T}$ interval was $0.56 \mathrm{sec}$. and the cycle $0.8 \mathrm{sec}$., so that $\mathrm{K}=0.63$, a very considerable increase; so great in fact that systole is twice as long as diastole instead of shorter than it. This resulted in a reversal of the heart sounds, the second occurring just before the first. As a consequence of the short diastole and inadequate filling of the ventricles, the first sound was short and sharp like a normal second sound, and therefore readily mistaken for it. The apparent proximity of the two sounds is explained by the fact that diastole is actually shorter than normal systole, as shown by calculating $\mathrm{K}$, using diastole instead of systole in Bazett's formula, when $\mathrm{K}$ is found to be $0 \cdot 27$ (normal systole $0 \cdot 36-0 \cdot 44$ ). The blood calcium was normal in this case, but there may have been a diminution of diffusible calcium (as has been postulated to explain the occurrence of tetany in alkalosis). Dehydration was here a pronounced feature, as it is also in diabetic coma and at one stage of chronic nephritis, and these two conditions are sometimes associated with prolongation of systole. Bazett's formula was 
therefore used to calculate $\mathrm{K}$ for two patients with dehydration but without alkalosis; normal figures were found.

From the slow circulation time and, at one stage, the raised venous pressure, it is evident that there was considerable impairment of cardiac function. Two factors were probably operative in its production. Firstly, the diastole was shortened, so that the great veins were not emptied completely before systole occurred. Secondly, the breathing was shallower and slower, due to the effect of alkalosis on the respiratory centre, so reducing the normal pumping action of the respiratory movements, particularly when, during the operation the respirations. were further depressed by the anæsthetic.

\section{SUMMARY}

The cardiographic findings in a severe case of alkalosis are described.

Marked prolongation of systole was present, so that systole came to be greater than diastole. This was associated with an alteration in the relationship of the heart sounds and impaired cardiac function.

The similarity to changes found in hypocalcæmia is discussed.

We wish to express our thanks to Dr. F. J. Power, Medical Superintendent of St. Nicholas Hospital, L.C.C., for facilities granted.

\section{REFERENCES}

Barker, P. S., Arbor, Ann, Shrader, E. L., and Ronzoni, E. (1939). Amer. Heart J., 17, 169. Bazett, H. C. (1920). Heart, 7, 353.

Carter, E. P., and Andrus, E. C. (1922). J. Amer. med. Ass., 78, 1922.

Graybiel, A., and White, P. D. (1941). Electrocardiography in Practice. 